\title{
Desempenho e Resposta Metabólica de Bezerros Recebendo Dietas Suplementadas com Cromo
}

\author{
Marcus Antonio Zanetti ${ }^{1}$, Márcia Saladini Vieira Salles ${ }^{2}$, Marcelo Landim Brisola ${ }^{3}$, \\ Marcelo Cerqueira César ${ }^{4}$
}

\begin{abstract}
RESUMO - Quatorze bezerros com quatro meses de idade, foram distribuídos em dois tratamentos, sendo um controle e um com suplementação de 0,4 mg de cromo orgânico por kg/M.S de ração basal. A ração basal foi constituída de 52\% de feno de coastcross e 48\% de concentrado à base de fubá de milho e soja extrusada, e foi oferecida ao animais durante 98 dias. Foi efetuado o controle diário da ingestão de alimentos. Na última semana foi realizado um teste de tolerância à glicose, com os animais em condições de conforto térmico. Para os grupos controle e tratado, o ganho em peso (1,330 e 1,320 kg/dia), a eficiência alimentar (0,24 e 0,25 kg) e a conversão alimentar (4,13 e 4,07 kg), foram semelhantes. Apesar de o grupo tratado apresentar tendência de eliminar a glicose mais rapidamente, os grupos não diferiram entre si.
\end{abstract}

Palavras-chave: minerais, tolerância à glicose, ganho de peso e eficiência alimentar

\section{Performance and Metabolic Response of Calves Fed Diets Supplemented with Chromium}

ABSTRACT - Fourteen dairy calves, four months of age were allocated in two treatments: control and supplemented with 0,4 ppm of $\mathrm{Cr}$ in the basal diet, which had $52 \%$ of grass hay and $48 \%$ of concentrate (corn meal and extruded soybeans) during 98 days. Feed intake was measured daily. In the last week were performed a glucose tolerance test. Performance were not affected by treatment (liveweight gain 1.330 and $1.320 \mathrm{~kg} / \mathrm{d}$; feed efficiency 0.24 and 0.25 and feed conversion, 4.13 and 4.07 for control and treated groups respectively). Chromium tended to decrease the blood glucose, but there were no statistical differences.

Key Words: glucose tolerance, minerals, weight gain, feed efficiency

\section{Introdução}

O cromo é um mineral que só recentemente passou a ser suplementado para ruminantes, havendo ainda uma série de dúvidas quanto aos seus reais efeitos. É sabido que o Cr potencializa a ação da insulina e desta forma atua na tolerância à glicose. Kelgey \& Spears (1995) estudaram os efeitos da suplementação com cromo orgânico utilizando bezerros Angus cruzados, durante 56 dias e concluíram que o desempenho não foi afetado com suplementação de $0,4 \mathrm{mg} / \mathrm{kg}$ de MS, entretanto, o cromo orgânico aumentou o nível de insulina sérica entre 15 e 30 minutos após a infusão de glicose. Apesar de não haver diferença significativa, nos animais que receberam o cromo orgânico, a glicose sérica tendeu a diminuir mais depressa no grupo controle, que não recebeu cromo orgânico $(\mathrm{P}<0,11)$.

Nos experimentos de Depew et al. (1998), a suplementação com o cromo tendeu a melhorar o crescimento de bezerros, mas não de bezerras Holan- desas. A ingestão de alimentos e a eficiência alimentar também não foram afetadas pela suplementação de cromo. Estes autores verificaram que o teste de tolerância à glicose é mais rápido em bezerros com duas semanas de idade do que com cinco semanas, e também não encontraram efeitos de suplementação com cromo no desaparecimento de glicose. No experimento de Chang \& Mowat (1992), foram estudados os efeitos da suplementação com cromo e/ou com oxitetraciclina, para bezerros de corte, com peso inicial de $245 \mathrm{~kg}$, em um período de 28 dias, logo após os animais chegarem de viagem depois de terem sido adquiridos em leilão. Posteriormente foi realizado um segundo estudo utilizando a suplementação com cromo e duas fontes de proteína, com duração de 70 dias. No primeiro período, que foi o considerado de estresse, a suplementação com 0,4 ppm de Cr (cromo levedura) propiciou aumento no ganho de peso dos animais tratados em relação ao grupo testemunha, sendo que nos grupos suplementados com oxitetraciclina , o cromo não teve efeito . No segundo período, quando 
não havia mais o estresse, os animais suplementados com cromo apresentaram o mesmo desempenho que os sem suplementação, tanto na dieta com uréia, quanto na com farelo de soja. Os ganhos obtidos na dieta com soja foram superiores aos com uréia. Os autores concluíram que a suplementação de cromo é importante em situações de estresse. Eles também estudaram a resposta imune e verificaram que a suplementação com cromo aumentou os níveis de imunoglobulinas.

Claeys et al. (1994) suplementaram dietas de novilhos (peso inicial de $332 \mathrm{~kg}$ ) com dois níveis de cromo $(0,4$ e 0,8 ppm) e três fontes (cr-cloreto, crpicolinato e cr-ácido nicotínico). Os autores após 84 dias de experimento não encontraram diferença para o ganho de peso e conversão alimentar entre os tratamentos. Tanto a glicose, quanto a insulina séricas não foram afetadas pela suplementação de cromo. Já no experimento de Hayirli (2001), as vacas leiteiras suplementadas no período pré-parto com cromometionina apresentaram aumento no nível de insulina basal em comparação com o grupo controle.

Um efeito do cromo que tem sido bastante pesquisado é na resposta imune, principalmente em animais submetidos à situação de estresse. No experimento de Moosie-shageer \& Mowat (1993), a suplementação com o cromo diminuiu as morbidades, assim como as temperaturas retais. A suplementação com o cromo propiciou uma maior concentração de imunoglobulina G1. Estes autores também notaram um aumento de $27 \%$ no ganho de peso e um aumento na ingestão de alimentos. Kegley et al. (1997), também verificaram aumento no ganho de peso de novilhos em crescimento, mas não notaram diferença na resposta imune, mesmo sob condições de estresse. No experimento de Burton et al. (1993), foi estudado o efeito da suplementação com $0,5 \mathrm{mg} / \mathrm{kg}$ de cromo em ração de vacas leiteiras, nas 6 semanas antecedentes ao parto e nas 16 semanas pós-parto. Os autores concluíram que a suplementação com cromo provocou um efeito significativo na resposta imune, tanto humoral quanto na mediada por célula, no período estudado que é considerado de estresse.

Danielsson \& Peherson (1998) realizaram experimento de suplementação com cromo-levedura (0,2 ppm) em ração de novilhos durante 170 dias, sendo que a dieta basal possuía nível de cromo de $0,72 \mathrm{mg} / \mathrm{kg}$. Não foram observadas diferenças entre os grupos, considerando o ganho de peso e os parâmetros de qualidade de carcaça, levando os autores a concluírem que na Suécia não há razão para suplementar cromo para bovinos em crescimento, alimentados intensivamente.

O objetivo do presente experimento foi estudar os possíveis efeitos da suplementação da ração de bezerros com cromo sobre o ganho de peso, a eficiência e a conversão alimentares e a tolerância à glicose.

\section{Material e Metodos}

O experimento foi realizado na FZEA (Faculdade de Zootecnia e Engenharia de Alimentos da Universidade de São Paulo ), campus Pirassununga. Foram utilizados 14 bezerros da raça holandesa em condições de conforto, com quatro meses de idade e $100 \mathrm{~kg}$ de $\mathrm{PV}$, em delineamento inteiramente ao acaso, distribuídos em dois tratamentos: ração basal suplementada com 0,4 mg/kg MS de cromo orgânico. A ração basal foi constituída de $52 \%$ de feno de coastcross e $48 \%$ de concentrado, com 71,8\% de fubá de milho, 25\% de soja extrusada, 0,3 de calcário, 0,9\% de fosfato bicálcico, $1 \%$ de sal mineral. A duração total foi de 98 dias, sendo 14 de adaptação e 84 de colheita de dados. A ração foi fornecida ad libitum e o consumo registrado diariamente para calcular a eficiência e conversão alimentar. Os animais foram pesados no início e no final do experimento, após um jejum de 16 horas. Na última semana foi realizado um teste de tolerância à glicose, que constitui resumidamente em retirar uma amostra de sangue com anti-coagulante (tempo zero) e, em seguida, injetar 0,5 g de glicose $/ \mathrm{kg}$ PV intravenosamente (solução a 50\%), em até dois minutos no máximo, sendo a cronometragem tendo sido iniciada 15 segundos após o início da injeção de glicose. A seguir passou-se às colheitas de sangue aos 5, 15, 25, 35, 45, 60 e 90 minutos, para verificar o desaparecimento da glicose. Para a análise estatística, inicialmente foi testada a homogeneidade das variâncias pelo teste $\mathrm{F}$ e a normalidade dos resíduos pelo Teste de SHAPIROWILK (Proc. Univariate do Statistical Analysis System (SAS, 1985), utilizando para as variáveis de desempenho o peso inicial como covariável. Os dados de glicose sangüínea foram analisados como Medidas Repetidas.

\section{Resultados e Discussão}

Ao final do experimento, que foi realizado em condições de conforto, foi verificado que não houve diferença na ingestão diária de matéria seca, ganho diário, eficiência e conversão alimentar ( $\mathrm{P}>0,05)$, 
tendo sido obtidos os seguintes valores: $5,510 \mathrm{~kg}$ e $5,370 \mathrm{~kg} ; 1,330 \mathrm{~kg}$ e 1,320 kg/dia; 0,24 e 0,25 e 4,13 e 4,07 para os grupos controle e tratados, respectivamente. Vários autores não têm verificado efeito da suplementação de cromo no desempenho de bezerros em condições de conforto (Kegley \& Spears, 1995; Depew et al., 1998; Danielsson \& Pehrson, 1998). Entretanto, Moonsie-Shageer \& Mowat (1993), encontraram aumento no ganho de peso diário, bem como na ingestão de alimentos por bezerros submetidos a estresse, mas não em situações normais. Kegley et al. (1997) também obtiveram aumento no ganho de peso com a suplementação com cromo, só que também com animais que foram submetidos a situações de estresse. No experimento de Chang \& Mowat (1992), os bezerros que sofreram o estresse do leilão e do transporte, nos 28 dias seguintes quando suplementados com 0,4 ppm de cromo ganharam mais peso que os não suplementados $(0,79$ versus $0,610 \mathrm{~kg} / \mathrm{animal} / \mathrm{dia})$. É interessante registrar que neste experimento, a suplementação com oxitetraciclina não teve efeito (0,79 e 0,80 kg/animal/ dia). Após o estresse, durante 70 dias, o cromo não teve efeito no desempenho animal, de modo semelhante ao ocorrido no presente experimento. Em condições normais, de modo semelhante ao obtido no presente experimento e também nos experimentos conduzidos no exterior, o cromo não tem apresentado efeito no desempenho animal, devido provavelmente aos níveis normais das dietas serem suficientes para adequado desenvolvimento. Uma das explicações para o melhor desempenho somente dos animais sob estresse é que nessas condições eles podem apresentar uma queda na resistência imune, como já comprovado em vários experimentos (Moonsie-Shageer \& Mowat, 1993; Burton et al., 1993), queda essa que comprometeria o desempenho e que a suplementação visando elevar os níveis de cromo evitaria.

A suplementação com cromo também não teve efeito significativo $(\mathrm{P}>0,05)$ no teste de tolerância à glicose, apesar de, como observado na Figura 1, ter sido constatada tendência de desaparecimento mais rápido da glicose sangüínea nos bezerros suplementados com cromo, de modo semelhante ao obtido por Kelgey \& Spears (1995), que também não encontraram diferença significativa no desaparecimento da glicose sangüínea, mas apenas tendência. Claeys et al. (1994) e Depew et al. (1998) também não encontraram diferença significativa no desaparecimento da glicose sangüínea. A tendência de

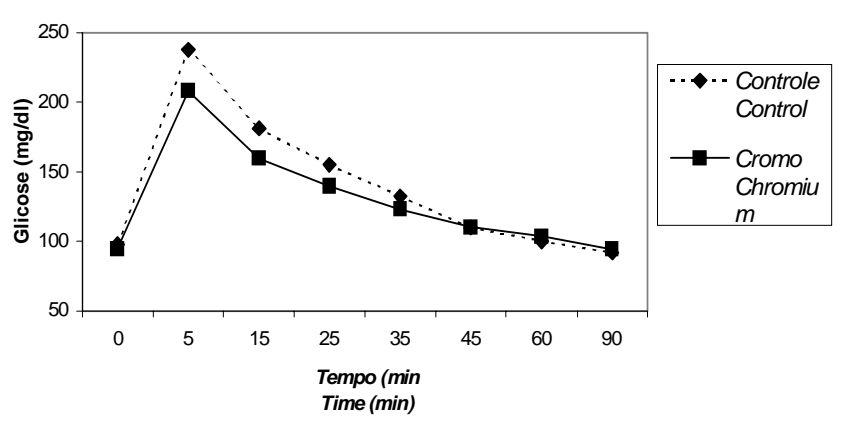

Figura 1 - Concentração de glicose no plasma. Figure 1 - Plasma glucose concentration.

desaparecimento mais rápido da glicose sangüínea é possivelmente devido a um aumento na atividade da insulina, como foi encontrado por Hayirli et al. (2001), suplementando vacas leiteiras no período do préparto com cromo-metionina e também por Kegley \& Spears (1995), que, suplementando bezerros mestiços Angus com cromo orgânico, por período de 56 dias, encontraram aumento no nível de insulina sérica, entre 15 e 30 minutos após a infusão de glicose.

Sob condições normais, ao que tudo indica, os níveis de cromo existentes nas dietas são suficientes para o desenvolvimento adequado dos animais, já em condições especiais, como em situações de estresse, vários trabalhos comprovaram um efeito positivo da suplementação com cromo orgânico. Na Suécia, em trabalho recente (Danielsson \& Pehrson, 1998), que não detectou efeito da suplementação com cromo levedura em ração de novilhos, os autores recomendaram que naquele país não deve ser feita suplementação para bovinos em crescimento, alimentados intensivamente. Seria interessante que fossem realizadas pesquisas visando verificar o efeito da suplementação com cromo para animais que são submetidos a condições especiais, como as de estresse, para verificar a real necessidade da suplementação, uma vez que uma preocupação que se deve ter constantemente é com a redução dos custos de produção, evitando gastos desnecessários.

\section{Conclusões}

A suplementação da dieta de bezerros não submetidos à estresse, com 0,4 mg de cromo orgânico por kg de matéria seca, não influenciou o desempenho e a resposta metabólica ao teste de tolerância à glicose. 


\section{Literatura Citada}

BURTON, J.L.; MALLARD, B.A.; MOWAT, D.N. Effects of supplemental chromium on immune response of periparturient and early lactation dairy cows. Journal of Animal Science, v.71, p.1532-1539, 1993.

CHANG, X.; MOWAT, D.N. Supplemental chromium for stressed and growing feeder calves. Journal of Animal Science, v.70, p.559-565, 1992.

CLAEYS, M.C.; SPEARS, J.W.; KEGLEY, E.B. Performance, blood metabolites and carcass characteristics of steers fes supplemental organic or inorganic chromium. Journal of Animal Science, v.72, suppl. 1, p.132, 1994.

DANIELSON, D.A.; PEHRSON, B. Effects of chromium supplementation on the growth and carcass quality of bull fed a grain-based diet during the finishing period. Journal of Veterinary Medicine, Series A-Pathology and Clinical Medicine, v.45, n.4, p.219-224, 1998.

DEPEW, C.L; BUNTING, LD.; FERNADEZ, J.M. et al. Performance and metabolic responses of young dairy calves fed diets supplemented with chromium tripicolinate. Journal of Dairy Science, v.81, n.11, p.2916-2923, 1998.

HAYIRLI, A.; BREMMER, D.R., BERTICS, S.J. et al. Effect of chromium supplementation on production and metabolic parameters in periparturient dairy cows. Journal of Dairy Science, v.84, p.1228-1230, 2001.
KEGLEY, E.B.; SPEARS, J.W. Immune response, glucose metabolism and performance of stresses feeder calves fed inorganic or organic chromium. Journal of Animal Science, v.73, p.2721-2726, 1995.

KEGLEY, E.B., SPEARS, J.W.; BROWN JR, T.T. Effect of shipping and chromium supplementation on performance immune response and disease resistance of steers. Journal of Animal Science, v.75, p.1956-1964,1997.

MOONSIE- SHAGEER, S.; MOWAT, D.N. Effect of level of supplemental chromium on performance serum constituents, and immune of stressed feeder calves. Journal of Animal Science, v.71, p.232-238, 1993.

STATISCAL ANALYSIS SISTEM - SAS. SAS User's guide: statistics. 5.ed., Cary: 1985.

Recebido em: 26/03/02

Aceito em: 03/02/03 